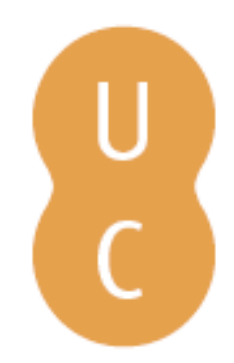

\title{
nombalina
}

\section{Edades y razas de la utopía griega}
Autor(es):
Campos Daroca, Javier

Publicado por: Imprensa da Universidade de Coimbra

URL persistente:

URI:http://hdl.handle.net/10316.2/32045

DOI:

DOl:http://dx.doi.org/10.14195/978-989-26-0499-2_3

Accessed : $\quad$ 26-Apr-2023 16:20:44

A navegação consulta e descarregamento dos títulos inseridos nas Bibliotecas Digitais UC Digitalis, UC Pombalina e UC Impactum, pressupõem a aceitação plena e sem reservas dos Termos e Condições de Uso destas Bibliotecas Digitais, disponíveis em https://digitalis.uc.pt/pt-pt/termos.

Conforme exposto nos referidos Termos e Condições de Uso, o descarregamento de títulos de acesso restrito requer uma licença válida de autorização devendo o utilizador aceder ao(s) documento(s) a partir de um endereço de IP da instituição detentora da supramencionada licença.

Ao utilizador é apenas permitido o descarregamento para uso pessoal, pelo que o emprego do(s) título(s) descarregado(s) para outro fim, designadamente comercial, carece de autorização do respetivo autor ou editor da obra.

Na medida em que todas as obras da UC Digitalis se encontram protegidas pelo Código do Direito de Autor e Direitos Conexos e demais legislação aplicável, toda a cópia, parcial ou total, deste documento, nos casos em que é legalmente admitida, deverá conter ou fazer-se acompanhar por este aviso. 
Maria de Fátima Silva

Coordenação

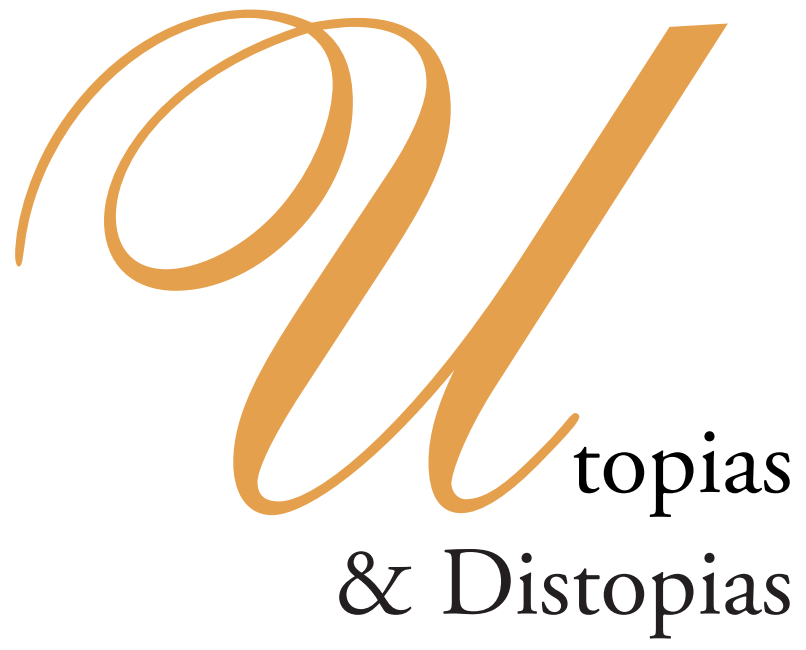




\section{COORDENAÇÃO EDITORIAL \\ Imprensa da Universidade de Coimbra \\ Email: imprensauc@ci.uc.pt \\ URL: http://www.uc.pt/imprensa_uc}

\section{CONCEPÇÃO GRÁFICA}

António Barros

Pré-IMPRESSÃo

Tipografia Lousanense, Lda.

EXECUÇÃO GRÁFICA

Tipografia Lousanense, Lda.

ISBN

978-989-8074-74-4

DEPósito LEGAL

289002/09

OBRA PUBLICADA COM O APOIO DE:

Centro de Estudos Clássicos e Humanísticos

Faculdade de Letras da Universidade de Coimbra

FCT Fundação para a Ciência e a Tecnologia

MINISTÉRIO DA CIÊNCIA, TECNOLOGIA E ENSINO SUPERIOR Portugal 
Maria de Fátima Silva

Coordenação
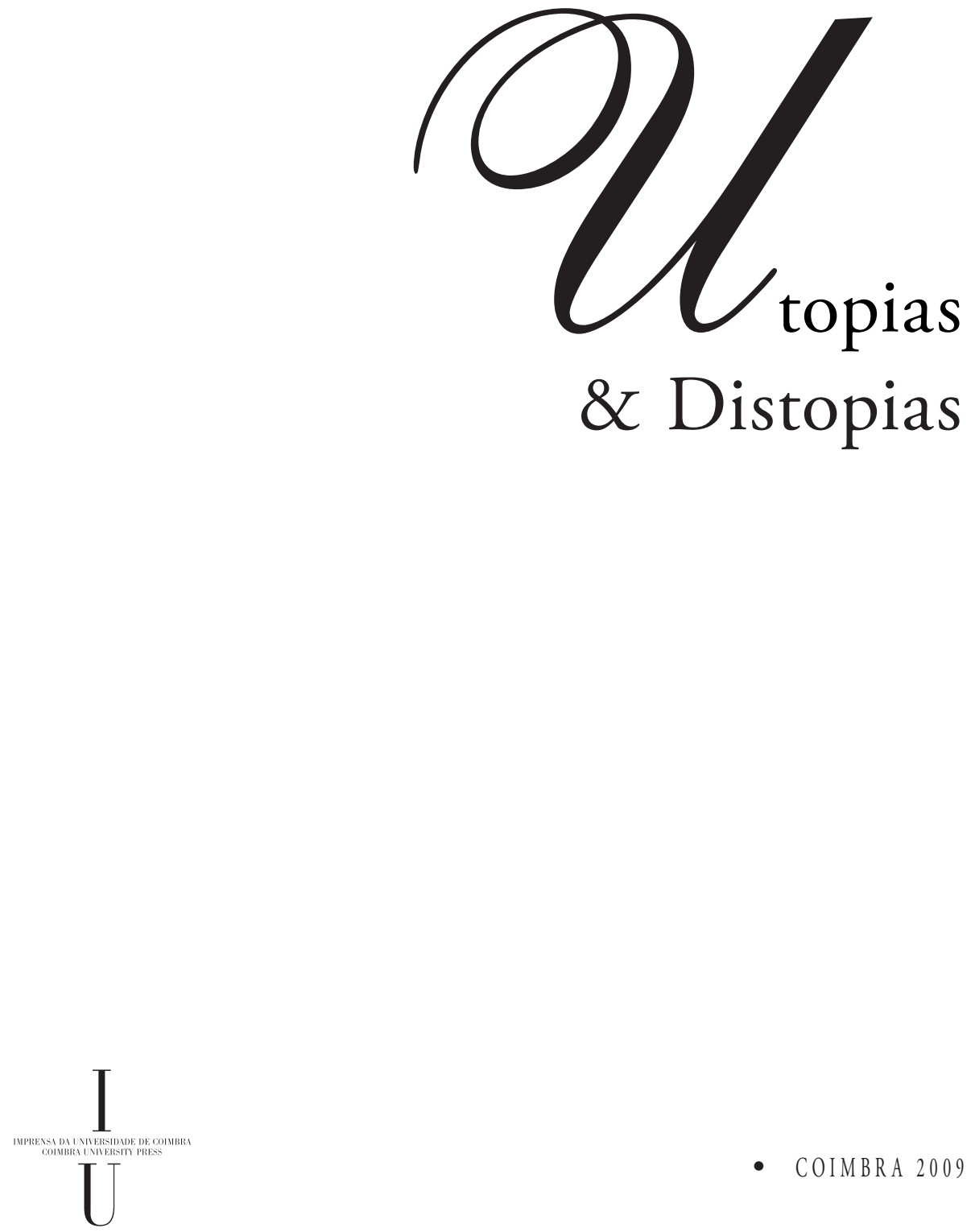

- colmbra 2009 

Javier Campos Daroca

EDADES Y RAZAS DE LA UTOPÍA GRIEGA

"Eres verdaderamente de oro", dice Sócrates a Fedro en un pasaje famoso del diálogo platónico en el que, por una vez, sorprendemos a Sócrates fuera de la ciudad sin razones de servicio (235e). Nos caben pocas dudas de que Platón hace en este punto del diálogo una alusión directa a la edad primera de la humanidad conforme al más prestigioso de los mitos griegos. De este modo integra el autor del diálogo una serie dispersa y aparentemente anecdótica de detalles aportados en la dramatización del encuentro de estos amigos que comparten una afición, la filología, que por entonces todavía significaba algo así como entusiasmo por la palabra ${ }^{1}$. El paraje en el que se sientan a departir largamente a la mitad del día está pintado con colores inequívocamente áureos y tuvieron como tales una prolongada descendencia en la literatura posterior. Los mitos evocados en la conversación son señaladamente historias de los orígenes, de criaturas fantásticas, de tiempos en que los hombres trataban con los dioses. Destacamos entre ellos la bellísima fábula de las cigarras, aquellos animales musicales que se olvidaron del alimento por causa del canto y que vigilan la interminable charla de los amigos. En este espacio consagrado a la conversación con todo el tiempo del mundo se suspende la premura de la vida de los hombres atareados por el sustento, y los privilegiados que allí se encuentran, Sócrates y Fedro, se dedican a la única actividad que Platón considera digna de la edad de Crono, si es que eran los de aquella raza hombres dignos de tal nombre. Es un lugar para gente sin cuidados y de una muy exigente religiosidad: un lugar, en suma, para hombres de oro. Platón ha construido a dos pasos de Atenas un lugar imposible para una raza de oro particular, como si fuera un cómico de los de la época dorada de la comedia griega. La calidad áurea de Fedro como interlocutor adecuado en este paraje extraordinario

\footnotetext{
${ }^{1}$ Entre los autores que han tratado estos pasajes introductorios destacamos a G.R.F. Ferrari, Listening to the Cicadas. A study of Plato's Phaedrus, (Cambridge, 1987), por su atención al espacio en que se desen vuelve este diálogo extraordinario. La pervivencia de este cuadro ameno para el diálogo filosófico ha sido adecuadamente tratado por M. Trapp, 'Plato's Phaedrus in Second-Century Greek Literature', en D.A. Russell (ed.), Antonine Literature, (Oxford, 1990), 141-173.
} 
donde sobreabunda la inspiración es, pues, la del viejo mito. Fedro lleva el rastro de los hombres felices y casi divinos ${ }^{2}$.

Por si fuera poco, Platón nos ofrece en este diálogo la única palabra que se acerca a significar en griego clásico aquello que se pretende hacer decir al término "utopía", forjado entre bromas por Santo Tomás Moro en un griego, todo hay que decirlo, muy particular. En los primeros compases del diálogo, Fedro había llamado a Sócrates "átopos" en superlativo, queriendo describir de este modo la extrañeza que le provocaba su amigo por su apego a los espacios ciudadanos (231c-d). Pero sería difícil y poco justificable no añadir a este sentido genérico de "raro" uno más fiel al etimológico, "fuera de lugar", descripción que cuadra muy bien a Sócrates y, tras él, a todos aquellos que siguieron con el mayor rigor su ejemplo. Sócrates, en efecto, andaba por la ciudad como si no estuviera en ella y proponía con su persona una enigmática idea de la política y, sobre todo, del político que parecía pensada para otras repúblicas. Los humanistas, que tuvieron a Sócrates por un santo, sabían bien que el efecto de una enseñanza exigente como la socrática o la de Cristo, puede dejarnos literalmente fuera de lugar y que ser intempestivo en lo que toca a principios se paga a veces caro. El propio Tomás Moro lo comprobó muy pronto. Así que, si bien el griego del nombre de la isla es dudoso gramática en mano, no cabe duda de que Moro entendió muy bien la paradoja platónica acerca de la naturaleza de su maestro insinuada en el adjetivo átopos, ni de que trasladó adecuadamente esa inspiración a sus fabulaciones de sociedades ideales que, en su extrańeza a veces hilarante, siempre crítica, brillaban esplendorosamente sobre el trasfondo de una historia tan atribulada como la que le tocó vivir y hasta protagonizar.

Lo que precede es un juego, pero es un juego muy serio, porque construir la historia de la literatura o de las ideas utópicas es indagar lo lugares que alojan los ideales humanos y sus inquietudes transhistóricas más graves, tomando como puntos de referencia la expresión que cobraron en la imaginación literaria, y hacer la crónica de esta exploración. Si hemos recurrido a un texto que suele quedar fuera de las historias de la utopía y lo hemos hecho hablar en el modo utópico ha sido para dejar claro cómo procedemos para encontrar los análogos de un género y un concepto cuando éstos están por inventar ${ }^{3}$.

Pero hay más. Es claro que la literatura clásica no es un campo cualquiera de proyección de la utopía en cuanto idea política moderna: es su matriz misma y suministra lo principal de su lenguaje, de modo que es perfectamente legítimo postular que la utopía es, en cierta medida importante, una de las posibilidades de un género más amplio que, falto como está de nombre, recibe el de una de sus especies. Así que, si exploramos los textos utópicos clásicos, no sólo podemos reconocer nuevas utopías o leer utópicamente nuevos textos, sino que podemos hacernos con su peculiar "gramática": la gramática de las ideas límites de las sociedades humanas cuando se ven forzadas a decirse y a representarse midiéndose con la realidad.

\footnotetext{
2 Sobre el valor simbólico del oro en la cultura griega arcaica y su presencia en el mito de las edades se ha extendido A.S. Brown, 'From the Golden Age to the Isles of the Blest", Mn 51 (1998), 384-410.

3 Sobre el tema de la aclimatación de e concepto y el género utópico a la literatura de la Antigüedad nos hemos extendido en J. Lens y J. Campos, Utopías del mundo antiguo, (Madrid, 2000), 5 ss., donde repasamos la bibliografía esencial.
} 
Seguimos, pues, el ejemplo del fundador del género, que admiraba a Platón y jugaba en griego, para hablar de lo más importante con gente que participaba de la broma y era plenamente consciente de la trascendencia de lo que se jugaba en ella. Hace falta a nuestro humilde entender sólo tres cosas: saber un poco de esa lengua en verdad utópica, sin patria y de nadie, libre en suma, que es el griego antiguo, conocer bien unos textos canónicos sobre los que, por lo demás, existe amplio acuerdo y, en fin, atenerse a unas pocas reglas, que no son sino corolarios de las propias de todas las ficciones sometidas a un imperativo modélico, para entregarse a uno de los juegos más serios que imaginarse puedan, como es el de pensar y describir sociedades casi impensables, la mejor o la peor de las sociedades humanas.

En estas líneas centramos nuestra atención sobre un texto castigadísimo en el canon de la historia de las utopías, uno de sus centros indiscutidos, como es el que narra la felicidad de los "hombres de oro", incluido en el conocido como "mito de las edades o razas" de Hesíodo, que podemos leer en la versión que nos ha llegado de Trabajos y dias $^{4}$, mito único en el repertorio de historias griegas de cuyos antecedentes en las literaturas orientales se ha especulado mucho ${ }^{5}$. De las reglas diremos que son simples y que se dejan describir como sigue. Hemos de hacer, en primer lugar, un distingo cualitativo fundamental e instalarlo en una de las dimensiones de la experiencia humana del espacio-tiempo. El griego humanístico se presta al juego de los nombres con la agilidad del clásico y nos brinda así las "utopías" y las "ucronías", según el eje dimensional que privilegiemos en esta primera maniobra ficcional. En tal enclave hemos de arriesgar una descripción "densa" de una sociedad diversa que polariza los modos de vida vigentes en el aquí y ahora discursivos. Esa descripción se atiene por lo general a lo que en otro lugar hemos llamado "tópica utópica", cuyos motivos fundamentales son tema de una ya extensísima literatura. Lugar de privilegio tiene en esta tópica la descripción de las condiciones de vida, sobre todo las que conciernen a la productividad natural de la tierra.

Un segundo momento de la construcción utópica requiere de nosotros que decidamos si la vida ideal conforme el tenor de la agentividad: distinguiremos, por seguir jugando en griego, las felicidades que sin más se disfrutan, que llamaremos "macarotopías", de aquellas en las que las condiciones de felicidad son el resultado de la acción y el esfuerzo humano, que pueden con propiedad denominarse "eupraxías"

\footnotetext{
${ }^{4}$ Seguimos la edición comentada de M.L. West, Hesiod. Works and Days, (Oxford, 1978), que citaremos en los sucesivo como West y número de páginas del comentario. Nos hemos servido igualmente de la colección de trabajos recopilados por E. Heitsch (ed.), Hesiod, (Darmstadt, 1966), donde se recoge lo esencial de la bibliografía más antigua. Sobre la compleja estructura del poema, además de las indicaciones de West, es clarificador el trabajo de M. Heath, 'Hesiod's didactic poem', CQ 35 (1985), 245-263. En lo sucesivo citaremos los versos de Trabajos y dias sin indicación de título de obra, que se añadirá en el caso de otras obras de Hesíodo.

${ }^{5}$ Los paralelos orientales de este relato han sido exhaustivamente revisados desde la pionera aportación de R. Reizenstein, 'Altgriechische Theologie und ihre Quelle', Vorträge der Bibliothek Warburg 4, (1924/ 5), 1-19 (recogido en Heitsch, Hesiod, 523-544). La tendencia actual es más bien a aceptar e incluso a extender esta dependencia. Una descripción somera del material disponible y el debate sobre el tema se encuentra en B. Gatz, Weltalter, goldene Zeit und sinnverwandte Vorstellungen, (Spoudasmata 16, Hildesheim, 1967), 8-27. West, 174-176, y con bibliografía actualizada en M. L. West, The East Face of Helikon. West-Asiatic Elements in Greek Poetry and Myth, (Oxford, 1997), 312-319. Conviene recordar que todas estas fuentes son posteriores a Hesíodo y que ninguna de ellas aporta un paralelo completo.
} 
y que suelen extenderse en un capítulo tópico que podemos, con Konstan, bautizar como las "nomías" 6 . Es este el caso de la isla de Utopo, de la que nos da noticia la obrita de Moro, de la cual no se nos ahorran detalles de la historia y progresos debidos a la providencia del rey, como tampoco de la labor de los isleńos, hacedores diarios de su felicidad.

Añadimos, finalmente, que las figuraciones utópicas se dividen según la polaridad del valor y el disvalor, de modo que el prefijo "dis-" sirve para construir el género gemelo de las pesadillas sociales, que en rigor podríamos llamar "kakotopías", una expresión que suena ciertamente mal, pero que recuerda de manera inusitada el nombre de una distopía egregia, como es la Kakania musiliana.

Atendiendo a los criterios que hemos puesto en juego, podemos decir que Hesíodo nos ofrece en el cuadro de la raza de oro incluido en el mito en cuestión una "macarocronía euéctica" ejemplar, madre de una larguísima descendencia que ha incorporado al léxico común, e incluso al lenguaje semitécnico de la historiografía literaria moderna, el adjetivo "áureo" para señalar y exaltar las obras y etapas canónicas?. Hesíodo, tal vez el primer autor de la historia literaria conocida, empeńó mucha "labor" en este mito de los Trabajos, por tomar una expresión que da cuenta de manera especialmente apropiada de la elaboración de las historias tradicionales asumida por primera vez en nombre propio por un poeta que se presenta sin ambages como inspirado por las instancias más autorizadas ${ }^{8}$.

${ }^{6}$ Cf. D. Konstan, 'The Greek Polis and its Negations. Versions of Utopia in Aristophanes' Birds', en G. Dobrov (ed.), The city as Comedy. Society and Representation in Athenian Drama, (Chapell Hill - London, 1998), 3-22.

7 La extraordinaria fortuna de esta narración singular, para la que estrictamente hablando no hay paralelo independiente en la mitología griega, ha sido trazada por Gatz, Weltalter, esp. 52 ss. y 114 ss. y H. Schwabl, 'Weltalter', RESupp. XV, 1978, col. 783-850. Entre los textos más relevantes de esta descendencia debemos contar los de Pl., Cr. 397e, R. III 415a, VIII 546e, Pol. 269a; Dicearco, ap. Porph., De Abst. 4, 2 (= fr. 49 Wehrli); Ap. Rh., IV 21461-2 ; Arat., Phaen. 96-136 ; Ant. Thes., Anth. Pal. V 31; Nig. Ph., De diis 4 (ap. Serv. In Verg. Buc. IV 10); Verg., Buc. 4; Hor., Ep. XVI 63-65; Ov., Met. I, 89-150; Iuv., Sat. VI; Sen., Oct. 391-437; Babr., Myth Aes. prol. 1-5; Orph., ap. Procl., a R. 2, 74, 26-30 Kroll = fr. 140 Kern. En las literaturas griega y latina los casos más conocidos de relatos que obervan con rigor la sucesión de los metales son los de Arato, Phaen. 100-136 (Oro - Plata - Bronce), Horacio, Ep. 16, 63-66 (Oro Bronce - Hierro), Ovidio, Met. I, 89-162 (Oro - Plata - Bronce - Hierro) y Juvenal, Sat. VI, 1, 1-24 (Oro - Plata - Hierro). Sobre la edad de oro en particular, el debate sobre la originalidad de Hesíodo ha tenido su debate específico. Por la originalidad se decantó H.C. Baldry, 'Who invented the Golden Age?', CQ n.s. 2 (1952), 83-92, a quien contestó J. G. Griffiths, 'Archaeology of Hesiod's five Ages', JHI 17 (1956), 109119, con un segundo turno en esta última revista: H. C. Baldry, 'Hesiod's Five Ages', JHI 17 (1956), 553 y J. G. Griffiths, 'Did Hesiod invent the Golden Age?', JHI 19 (1958), 91-93.

${ }^{8}$ La compleja configuración enunciativa de los poemas de Hesiodo, expresada en los proemios de Teogonía y Trabajos, ha sido objeto de un interés considerable como testimonio excepcional de la poética arcaica y sus transformaciones. El caso de Trabajos ha sido estudiado en detalle por P. Rousseau, 'Instruire Persès. Notes sur l'overture de Travaux d'Hésiode', en J. Blaise - P. Judet De la Combe - Ph. Rousseau (eds.), Le Métier du mythe. Lectures d'Hésiode, (Lille, 1996), 93-168 y C. Calame, 'Le proème des Travaux d'Hésiode. Prélude a une poésie d'action, Ibidem, 169-190. La expresión de trabajo sobre el mito se debe a H. Blumenberg, Trabajo sobre el mito, (Barcelona, 2003). 
El texto de referencia, los versos 109-126 de Trabajos, es de una simplicidad engañosa, sobre todo si se contempla en los estrictos términos de una antología que busque sólo sus cualidades tópicas. Pero si lo restituimos a su situación orgánica dentro del llamado mito de las razas y, más allá, al conjunto de la obra hesiodea, descubrimos uno de los textos más ricos y complejos de toda la literatura griega. Paradójicamente, todos los textos posteriores que lo toman como referente modélico, pertenecientes por tanto a una cultura literaria más refinada por libresca, no hacen sino simplificar y someter a una ley histórica homogénea la línea sinuosa con la que inevitablemente representamos el discurrir de las edades de los hombres en el relato hesiódico? . De este modo instalan a los hombres de oro en una polaridad simple que banaliza el relato de Hesíodo.

En efecto, el interés suscitado por el cuadro hesiódico de la primera generación humana como fabulación utópica ha tenido como contrapartida un efecto textualizador que ha acabado por desentrañarlo de su lugar en una composición que, por otro lado, parece prestarse con facilidad a ello. De este modo el mito se ha constituido en texto, por hablar con Calame y, como tal, se ha recibido exento de su medio poético inmediato, en el que ocupaba el centro de una serie narrativa con una importante función argumentativa, en un poema que se construye como un extensa amonestación. La textualización a la que nos referimos toca al mito que nos concierne por partida doble. No es sólo la relación de las razas humanas la que se ha extraído de su lugar en el medio de otros mitos de Trabajos, sino que la descripción de la estirpe áurea ha gozado de suerte independiente de la sucesión de las edades, como prototipo de cuadro de la vida mejor y, como tal, figura en las numerosas antologías e historias de la utopía y figuraciones relacionadas. Nos toca, por tanto, un doble esfuerzo de integración, un trabajo sobre el mito que secunde el esfuerzo orginal del poeta al que las musas concedieron sus mejores mieles.

Empezamos por una cuestión léxica que consideramos de importancia, pues puede tomarse como óla primera evidencia del trabajo que Hesíodo se tomó en Trabajos para hacer hablar a un mito extraño en términos indígenas. La dimensión en la que se establece la diferencia resulta de una combinación de tiempo y fisiología que se expresa en el tér-

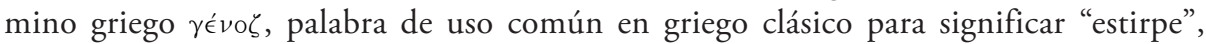
"generación” e incluso "clan”, y que Hesíodo fuerza aquí a una significación inédita, para cuya traducción, siguiendo el método de los humanistas, nos servimos de dos palabras, "raza" y "edad", cuyos sentidos hemos de unir en la mente ${ }^{10}$. Son estas "edades-razas",

9 Según G. W. Most, G. W. 'Hesiod's myth of the five (or three or four) races', PCPhA 43 (1997), 104-127, las operaciones más habituales aplicadas a la adaptación del texto han ido en el sentido de simplificar y homogeneizar: abrevian eliminando los detalles irrelevantes de modo que resulte una narrativa coherente de declinación lineal. Casos especiales son los de Firm. Mat., Math. III 1, 1-15, que presenta una secuencia de cinco edades y los Oráculos Sibilinos I, 1-2, 13, donde el texto es expandido hasta diez razas. El interés del pasaje de Fírmico está en que no parece tener conexión alguna con los poemas hesiódicos. Los oráculos requieren tener en cuenta la literatura judeohelenística. Acerca de su fortuna como modelo historiográfico, sobre todo en la literatura romana, cf. H Schwabl, 'Zum antiken Zeitaltermythos und seiner Verwendung als historiographisches Modell', Klio 66.2 (1983), 405-415, quien aporta pasajes de Pompeyo Trogo (ap. Iust. I 1, 1.3), Tácito, Anales III 26 y Séneca, Ep. XC (quien toma inspiración en Posidonio).

10 Cf. T.G. Rosenmeyer, 'Hesiod and Historiography', Hermes 85 (1957), 265-267, señala que Hesíodo fue el primero que formuló una visión epocal de la historia. 
unidades colectivas de orden cronobiológico, épocas cerradas por una raza de hombres que se distinguen por una manera distintiva de "vida" y una edad ${ }^{11}$, las que constituyen los sujetos de este mito singular de protagonistas colectivos ${ }^{12}$. Ciertamente, cuando hablamos del "hombre del Renacimiento" y lo distinguimos del "hombre medieval" y prescindimos de toda idea de progresión histórica, no nos expresamos de manera muy diferente. La raza de oro es una entre las cinco de la especie humana que se suceden en cinco tiempos, de modo que hacen imposible una genealogía unitaria para el conjunto de la especie. Si bien la bondad de los hombres de oro permanece en forma demónica, nuestra relación con ella no es genealógica, sino afín a la que tenemos con los dioses, de los que son, tras su muerte, una especie menor. La genealogía de los dioses procede sin solución de continuidad, la de los hombres está irremediablemente fragmentada en el seno mismo de la especie.

Parece que urgido por esta diferencia del tiempo humano, que se constata sólo cuando se ve en el trance de contar la historia humana, Hesíodo ha elaborado el vocabulario para designar estas grandes especies de seres vivos que comparten el universo tan desigualmente. Y en efecto, si comparamos el léxico de la Teogonía en este campo observaremos que en este poema sigue vigente la posibilidad de referirse a la

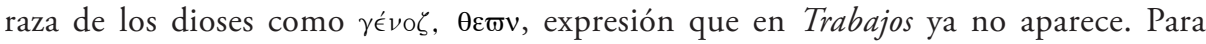
designar los géneros supremos de seres vivos Hesíodo, biólogo avant la lettre sensible al léxico clasificatorio, especializa en Trabajos el sustantivo $\varphi \mu \lambda \mathrm{ov}^{13}$, y distingue el de los dioses del de los hombres, irremediablemente plural. Para esta pluralidad humana

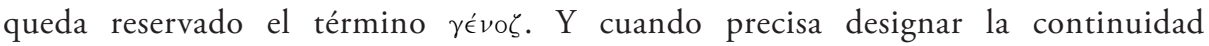
generacional, Hesíodo recurre al vocablo $\gamma \in v \in \eta$ '. Pero si aceptamos este matiz léxico nos encontramos con la curiosa consecuencia de que la serie de edades no es igualmente discontinua en todas sus coyunturas: la que separa la edad de los héroes y la de hierro no es una solución de continuidad, como demuestra el hecho de que el texto se expresa de manera mucho menos terminante en este caso sobre el fin de los héroes y el nacimiento de los hombres de hierro ${ }^{14}$.

11 P. Smith, 'History and Individual in Hesiod's Myth of Five Ages', CW 74 (1980), 145-163, toma esta característica como argumento para sostener su interpretación "psicológica” del mito hesiódico. Las edades sucesivas lo son del hombre como ser vivo y representan su curso desde la infancia a la vida adulta, que se resume en la aceptación de la triste condición de la existencia humana. Es específico del uso que hace Hesíodo de la simbología de los metales que éstos no se mezclan, cf. West, East Side, 312: cada raza tiene las características del metal puro.

12 El único personaje singularizado es Zeus, cuyo poder y autoridad domina toda la primera parte del poema. Rosenmeyer, 'Hesiod and Historiography', 279, quien ha destacado este rasgo del mito, considera que incluso el nombre de Zeus en este mito debe interpretarse en términos abstractos, no como el dios singular que parece denotar.

13 En el léxico de la filiación genérica, el término phylon es en Trabajos común a dioses y hombres, cf. 199-200, phylon athánaton / phyla antropon 90 (nótese el uso del plural en el caso humano). Genos se reserva para la filiación genérica humana.

${ }^{14}$ Cf. Ch. Sourvinou-Inwood, 'The Hesiodic Myth of the Five Races and the Tolerance of Plurality of Greek Mythology', en O Palagia, (ed.) Greek Offerings. Essays on Greek Art in Honour of John Boardman, (Oxford, 1997) 1-21, quien subraya el valor de esta continuidad. Conviene destacar que el verbo utilizado para designar el acto de creación recurrente de las razas humanas por parte de los dioses es siempre poieîn en aoristo $(109,128,144,158)$, excepto posiblemente en el caso de los hombres, donde el papiro berlinés que aporta los versos $173 \mathrm{a}$-d permite la reconstrucción, the [ke en 173d, propuesta por Wilamowitz y aceptada por West y los editores posteriores. West 1978: ad. loc. apunta Alcman fr. 20 Page (PMG) como pasaje 
Teniendo en cuenta esta diferencia en el régimen de la temporalidad humana, en la que Hesíodo asienta su raza utópica, conviene en segundo lugar no perder de vista la serie de la que esa raza de oro constituye un primer eslabón. En efecto, al ubicarlo en la serie de razas humanas encontramos que la polaridad valorativa, que acompańa ineludiblemente a los textos utópicos, no es la simple y común que encontramos, por ejemplo, en el liber vere aureus de Moro, sino que aparece complicada por dos factores que enunciamos brevemente: una gradualidad ambigua en el tenor valorativo de la sucesión, que desdibuja los contornos de la perfección en la serie de las edades, y una recurrencia de los motivos áureos que pone la edad de oro en competencia con otras edades de la serie y, más allá, con elementos externos al mito de las edades dentro de Trabajos.

En cuanto a la gradación de las edades, la edad de oro, muestra esta resistencias al esquematismo, tanto en su versión lineal-histórica, en sus formas clásicas de decadencia o degeneración, como en la estructural. El esquema que asumimos quiere aprovechar las variadas propuestas exegéticas que ha suscitado este texto indócil, propuestas entre las que hizo época la estructural de Vernant ${ }^{15}$. La exploración más reciente vuelve a dar valor al eje histórico, que siempre ha sido uno de los aspectos más controvertidos de la lectura estructural ${ }^{16}$. Nos ha parecido especialmente convincente la lectura de

paralelo de este uso del verbo para describir la creación divina. West señala que este uso es muy antiguo, como testimonian los textos védicos, y añade como usos relacionados Homero, Ilíada I 2, y IX 547. La cualidad técnica de la fábrica humana es muy detallada en el caso de la mujer (59-82), donde el verbo títhemi aparece repetidamente para describir la actividad de los dioses (61, 67, 74, 79). Es interesante constatar que, según el fr. 204 W.-M. describe, el final de la edad de los héroes en términos de "cambio climático" (la expresión no es de Al Gore: es de West, 174). La edad de los héroes tenía en las tradiciones griegas, por lo demás, también sus épocas (que insinúan ya la distinción entre dos edades de la guerra): antes de los héroes de Tebas y Troya se situaban historias de personajes más rudos y violentos, entre los que destaca Heracles, cuyas historias fueron pronto en la cultura trágica griega ejemplo de las ambigüedades de la fuerza. Los escolios identifican de hecho a los hombres de la edad de bronce, nacidos de los fresnos (ek melian, 145), con los gigantes, que en la Teogonía 50 son asociados a los hombres a tenor de su violencia, mientras que en 185 ss. se refiere brevemente su nacimiento de las gotas de sangre de Urano, recogidas por Gea quien, "al completarse un ańo, dio a luz a las poderosas Erinias, a los altos Gigantes der resplandecientes armas y a las ninfas que llaman Melias sobre la tierra ilimitada”.

15 Como es ya sabido la interpretación de J. P. Vernant, 'Le mythe hésiodique des races. Éssai d'analyse structural', Revue de l'histoire des religions, 157 (1960), 21-54, seguía la estela del artículo pionero de V. Goldsmith, 'Theologia', REG 63 (1950), 20-42 y fue contestado críticamente por J. Defradas, 'Le mythe hésiodique des races. Éssai de mise au point', L’information littéraire, 17 (1965), 152-156, a quien, a su vez, contestó J. P. Vernant, 'Le mythe hésiodique des races. Sur un éssai du mise au point', RPh 40 (1966), 247276. A partir de estos trabajos toda discusión sobre el tema tiene que tomar posiciones frente a las propuestas de Vernant, que siguen teniendo amplia aceptación, cf. la revisión de L. Coloubaritisis, 'Genèse et structure dans la mythe hésiodique des races', en Blaise - Judet de Lacombe - Rousseau, Le Métier du mythe, 479-518. Es, sin embargo habitual señalar las insuficiencias del modelo estructural. Las precisiones de detalle son especialmente iluminadoras, por ejemplo la que plantea Brown, 'Gold Age', 392-393, respecto del valor simbólico del oro, que Vernant relacionaba fundamentalmente con la realeza en su premura por acomodar las razas hesiódicas al esquema tripartito de su admirado Dumézil (a quien había remitido el trabajo primero), pero que en la Grecia arcaica tiene asociaciones simbólicas no con la realeza sino con la divinidad.

${ }^{16}$ C. Calame, 'Succesion des âges et pragmatique poètique de la justice: le recit hésiodique des cinq spèces humaines', en Pratiques poétiques. Représentations de l'espace - temps en Grèce ancienne, (Paris 2006), 85-142. Los primeros intentos de interpretaciòn del mito constataron, en efecto, que la secuencia de las edades integra dos líneas incompatibles, la de la decadencia respecto de la vida idílica, y la paradigmática que sitúa en el pasado inmediato una época heroica; en la secuencia de conjunto, la edad de los héroes, 
Strauss-Clay ${ }^{17}$, que hemos seguido más de cerca, es que da todo su valor a la estructura de sucesión y a sus singularidades. Esencial nos parece la que llamaremos "singularidad de la justicia", que no podemos entender como un elemento recurrente en los diversos niveles de una tripartición funcional, à la Vernant, sino como un acontecimiento singular en el proceso de configuración de lo humano llevado a cabo a iniciativa de unos dioses que, estructuralistas sin saberlo, parecen desear de pronto distinguirse y buscan denodadamente un género que les deje ver con claridad la hermosa vida que llevan ${ }^{18}$.

La figura de Zeus hace época de la manera más terminante en la sucesión de las edades de los hombres. Con él se separan definitivamente las suertes del hombre y del dios en cuanto al género de vida: al hombre le toca en lo sucesivo una vida penosa y la reproducción mediada por la mujer; al mismo tiempo, hace aparición con Zeus un valor que lleva las condiciones áureas más allá del simple estar bien de los hombres de oro. Y con Zeus aparece, en rigor, la justicia, un momento tanto más importante cuanto que previamente se había insinuado en el paraíso un "adelanto" de la injusticia: en efecto, la primera edad de la humanidad está dividida por el paso negativo dado por los hombres de la raza de plata. La justicia de Zeus, vigente por fin en la raza de los héroes, es respuesta firme y poderosa a una deriva que ya es propia de las razas más nobles, pero que sólo podemos nombrar como injusticia a posteriori. Surge en la raza de plata, que es, con mucho, la raza más misteriosa e inquietante de la serie. Pertenecen sus hombres según toda apariencia a la edad del gobierno de Cronos, pero en ella se han de suponer ya vigentes cambios sospechosos: hay resquemores entre dioses y hombres, hay altares y, si no hay padres, sí que hay madres y muy cuidadosas de sus hijos ${ }^{19}$. Así pues, en el proceso que lleva de la edad de plata a la de bronce hay que situar en un eje de simultaneidades los actos fundantes de la variedad de humanidad a la que pertenecemos: gobierno de Zeus, vida difícil alejada de los dioses, sufrimiento y mujer. La edad de oro, como la de plata, es en puridad "anómica": el protagonismo de los hombres de tiempos de Crono no es del orden de los modelos eunómicos del utopismo clásico, sino de los estadios previos a cualquier esfuerzo civilizatorio, vida cercana y comunicada con animales y dioses.

En segundo lugar, considerado el texto en la serie que le corresponde por iniciativa

irrenunciable para alguien que cantara en la Grecia arcaica, se encuentra cuestionada en su misma ejemplaridad. La lectura por estructuras encontraba una salida elegante recurriendo a la desconsideración de la historia, y se hacía fuerte en la soluciones de continuidad marcadas en el mito como con voluntad clasificadora, así la que se subraya entre las razas de plata y bronce.

17 J. Strauss-Clay, Hesiod's Cosmos, (Oxford, 2003).

18 Sobre la singularidad de la justicia en la secuencia de las edades han sido especialmente elocuentes A. Neschke, 'Dike: La philosophie poétique du droit Dans le myhe des races d'Hésiode', en Blaise - Judet de Lacombe - Rousseau, Le Métier du mythe, 465-478 y recientemente, Strauss-Clay, Hesiod's cosmos, 75 ss., quienes cuestionan la generalización de la misma en forma de "rasgo" para construir a partir de la relación hesiódica una estructura de simetrías, siempre demasiado proporcionadas.

${ }^{19}$ Sobre la correspondencia entre la serie divina y la humana de las generaciones caben posiciones econtradas, dado que los versos no son al respecto lo suficientemente explícitos como para aclarar la cuestión. SourvinouInwood, 'Hesiodic Myth', 2-3, se decanta con razones que nos han convencido por la cronología relativa que hemos seguido en este trabajo y que pone a los hombres de plata bajo el reinado de Crono, Subraya la autora que la raza de plata es el complemento apropiado de la de oro por aportar los elementos negativos que en la antigüedad distinguen al reinado de Cronos con tanta propiedad como los idílicos. 
poética, encontramos que los cuadros de la condición ideal de la vida humana aparecen por lo menos en cuatro ocasiones de la primera parte de Trabajos, de modo que la edad o raza de oro de Hesíodo ve, por segunda vez, relativizada su excelencia. Llamamos a esta recurrencia utópica, esa isotopía de los tiempos mejores en la primera parte de Trabajos, "correlación áurea". En efecto, el privilegio de la despreocupación completa lo disfrutaron sucesivamente $a$ ) los hombres que vivieron antes de la creación de la mujer (90-92), b) las criaturas de oro creadas primero por los dioses $(112-115), c$ ) los héroes de Zeus trasladados a las Islas Felices (165-173) y d) los hombres que gozan del privilegio de gobernantes justos (225-237). La correlación áurea dota, en suma, de unidad temática (en el sentido musical de tema) a la primera parte del poema dedicada a exhortaciones a Perses para que sea trabajador y justo. Apunta ya en la primera reconvención que se hace a los jueces por su ignorancia del verdadero provecho (40-46), se perfila en el mito de Pandora, se desarrolla en las edades humanas de manera gradual y alcanza el mayor detalle tras las negrísimas tintas de la edad de hierro, más oscuras aún por la desoladora lección del halcón al ruiseñor, con un cuadro de la felicidad humana en la ciudad justa, en la que el hombre tiene un protagonismo decisivo.

Así pues, la raza de oro hesiódica, lejos de quedar encerrada en el mito de la sucesión de las razas humanas humana, se compone de manera dinámica a lo largo de una secuencia que lo entrelaza con el entorno poético y nos permite recorrer "variedades de utopía" en razas y edades diferentes. De este modo, por tomar un ejemplo, la ausencia de penalidades aparece en tres de las versiones relacionada con la fertilidad natural de la tierra, pintada de maneras sustancialmente diferentes en la raza de oro, donde el fruto espontáneo es mucho y abundante sin más (116-120, no entramos por ahora en la disputada autenticidad de éste último verso), en las islas de los héroes, donde las cosechas son tres al año, de frutos dulces como la miel (173-174), y en las ciudades justas, donde se detalla feracidad de los espacios salvajes y cultivados, la fertilidad de los rebaños y de las mujeres, integradas esta vez explícitamente en un cuadro de felicidad humana (231-237). También hace Hesíodo explícitas en este último caso las ausencias que acompañan a la exención del trabajo penoso: las guerras y el comercio ultramarino. Respecto de la primera ausencia al menos, la de la guerra, la raza de los hombres justos parece superior a la de los mismos héroes, que no gozaron ciertamente de un mundo pacífico.

El recorrido de las edades del hombre está, pues, muy lejos de ser recto conforme a una orientación exclusiva. Sigue un trazo sinuoso que no se atiene de manera inequívoca a ninguna ley histórica, como tampoco a una que permitiera construir un sistema de nociones culturales de amplio espectro. En su progresión leemos ya progresos ya regresiones civilizatorias e, incluso, un auténtico punto de indeterminación, que coincide con el presente de la enunciación enunciada del poema, abierta a la más desgraciada de las condiciones, pero también a una paradisíaca por el trabajo. Para quien estudie la historia de las fabulaciones utópicas lo más interesante de este mito es que el cuadro de vida ideal es descompuesto en diversos momentos de la historia humana al mismo tiempo que, gracias al complejo entramado de referencias entre esas refracciones, el mito es proyectado más allá de la sucesión misma, en el futuro indeterminado de una raza de hierro que vive muy cercana a la de oro. Ahora bien de la primera a la última variante de la correlación áurea, ya fuera del mito, en pleno futuro histórico, ha cambiado un signo fundamental en la valoración de las fabulaciones 
utópicas: la actividad humana y su responsabilidad en el bienestar del que se disfruta en la ciudad justa ha cobrado un protagonismo inédito respecto al de los hombres de oro. Estamos ya ante una "eupraxía eunómica", muy lejana de la "makarotopía anómica" de las edades de los metales más nobles.

\section{III}

En el cuadro de la felicidad áurea que nos brinda Hesíodo para la primera de sus razas, hay dos versos que plantean dificultades al intérprete guiado por las expectativas de una materia tan fuertemente sometida a la lectura tópica. La curiosidad de los versos reside en el hecho de que van en rigor contra uno de los motivos fundamentales del mito de la edad de Crono. En efecto, en la tópica utópica constitutiva de los mitos paradisíacos tiene un lugar de privilegio el motivo que podemos llamar el "automatismo de la tierra", si damos a la palabra "automatismo" un sentido fiel a su etimología: el de la productividad espontánea sin necesidad del esfuerzo humano. El motivo, que alcanza un desarrollo espectacular y muy variado en la comedia antigua, es tan corriente que, al cabo, se integra en el acervo de las expresiones sentenciosas ${ }^{20}$. Tiene, lo hemos visto, un protagonismo bien visible en la correlación áurea hesiódica, como revela un cotejo de los textos pertinentes.

Ahora bien, los versos 119-120 interrumpen el flujo natural de la lectura tópica. Por empezar con el menos problemático, el 120, que cierra la descripción, nos habla de hombres ricos en ganados, pero es un verso que conocemos sólo por la tradición indirecta, gracias a la extensa cita que Diodoro de Sicilia hizo en el libro V de su Biblioteca Histórica, un aval poco fiable ${ }^{21}$. El testimonio de Dicearco, quien no lo incluye entre los versos hesiódicos citados en su Vida de Grecia para ilustrar la vida primitiva, consolida la sospecha, aunque las razones de esta omisión están posiblemente en relación con sus peculiares ideas sobre el proceso de las edades del hombre, que sólo en un segundo estadio contempla la aparición de la propiedad y la riqueza junto con el consumo de carne animal ${ }^{22}$. Así las cosas, la solución más razonable parece ser la de poner en cuarentena el verso, como hace West y, con él, la mayoría de los edito-

${ }^{20}$ Cf. Gatz, Weltalter, 114-128. La literatura sobre el tema es ya considerable, pero hay que destacar el trabajo de M. Farioli, Mundus alter. Utopie e distopie nella commedia greca antica, (Milán 2001) así como el de A. Melero en este mismo volumen. Los textos de referencia, además del abundante filón de comedias aristofánicas conservadas, como Acarnienses, Paz o Aves, son los conocidos fragmentariamente del propio Aristófanes, Freidores (fr. 504 K.-A.), Estaciones (fr. 581 K.-A.); de Cratino, Plutos (fr. 176 K.-A.) y Leyes (fr. 131 K.-A.); de Crates, Bestias (fr. 16-17 K.-A.); de Teleclides, Anfictiones (fr. 1 K.-A.); de Ferécrates, Mineros (fr. 113 K.-A.) y Persas (fr. 137 K.-A.); de Metágenes, Turiopersas (fr. 6 K.-A.); y de Nicofonte, Sirenas (fr. 21 K.-A.). En la comedia media se señalan los casos de Eubulo, Olbia; de Antífames, Enomao y de Aristofonte, Pitagorista. En la comedia nueva se cita la obra de Dífilo, El insaciable. Sobre las sentencias derivadas de este tópico, cf. Gatz, Weltalter, 119.

${ }^{21}$ Cf. Diodoro, V 66, 6, donde se citan los versos 110-120 en el contexto de la descripción de Sicilia. En la versión de Diodoro en el reinado de Crono los hombres abandonaron la forma bestial de vida y gozaron de las condiciones propias de la raza de oro, para ilustrar las cuales Diodoro refiere los mencionados versos.

22 El fragmento de Dicearco es conocido por la extensa cita que debemos a Porfirio, Sobre la abstinencia 4, 2, 1-8 (49 Wehrli = 56A Mirhady). Sobre los problemas de la reconstrucción de la Vida de Grecia, cf. T. J. Saunders, 'Dicaearchus Historical Anthropology', en W. W. Fortenbaugh - E. Schütrumpf (edd.), Dicaearchus of Messana. Text, Translation and Discussion, (New Brunswick - London 2001), 237-254. 
res $^{23}$. Pero es igualmente posible que la seclusión fuera antigua, operada ya por eruditos de Alejandría, incomodados por la misma incoherencia que los modernos.

Sin embargo, lo cierto es que esta prosperidad de los rebaños es perfectamente coherente, tanto en la serie de la correlación áurea, si tomamos en consideración sólo el texto de Hesíodo, como en la que se genera intertextualmente en el género épico, si traemos a colación el conocido cuadro de la vida de los Cíclopes. En la edad de los héroes Hesíodo hace mención de los rebaños en relación con una de las grandes empresas en las que se empeñan los hombres de esa edad para su exterminio, la lucha por las reses de Edipo hacen pareja ni más ni menos que con la expedición a Troya para recobrar a Helena (163). Si bien esto puede ser argumento para reafirmarse en la atétesis, lo cierto es que con más razón puede invitar a la aceptación. De lo que se trata, en definitiva, es de destacar el contraste entre las edades, y para ello es especialmente eficaz el procedimiento de señalar las diferencias a partir de elementos análogos. En este sentido, las "ovejas" de los hombres de oro en su abundancia se distinguen por no ser objeto de riñas destructivas, mientras que son ocasión de pleito para los héroes. Los rebaños de los hombres de oro completan un cuadro de abundancia natural y no conflictiva que redunda en la caracterización de la raza como un dion genos.

El verso 119, sin embargo, plantea una incongruencia mucho más difícil de solventar, cuando afirma que los hombres de oro, pese a la prosperidad de la que gozan, se aplicaban a sus tareas, eso sí, con todo contento y despreocupación. Qué tareas puedan ser éstas en una edad en que la tierra daba todo con gratuidad espontánea es la pregunta que suscita este verso incómodo de este ya de por sí mito indócil. En los paralelos orientales puestos a colación por West no se encuentra análogo para esta labor sin pena en los cuadros de felicidad humana, que lleva indefectiblemente aparejada ausencia de todo trabajo ${ }^{24}$. En este caso, además, no podemos recurrir fácilmente al expurgue, dado que el verso está atestiguado unánimememnte por toda la tradición manuscrita con variantes de poca importancia.

Todo se juega en el sentido que postulemos para el sintagma erga enemonto, que puede domesticarse hasta hacerle significar cualquier cosa o por el contrario respetarse. El comentario a este pasaje de West es de probidad ejemplar al dejar constancia de la perplejidad que el verso suscita: las actividades de estos hombres felices son también erga, un término que por sus connotaciones de "tillage" parece "poco apto" para describir la vida bajo Crono. Cabe atribuir el peso de esta incongruencia al efecto de un lenguaje formular aplicado a una materia novedosa, como sin duda era el mito de

23 West, señala, por otro lado, que el verso tiene una apariencia bastante hesiódica (cf. v. 234 y frs. 23 (a), 32-33 y 240 M.-W.) y que puede perfectamente remontar a versiones "wild" del texto. Es posible que Orac. Sybil I 72 s. sea un eco del verso en cuestión. Entre los editores sólo Evelyn-White mantiene la línea y la conecta con el fr. 1 M.-W.

${ }^{24}$ En los relatos orientales la edad de oro es sobre todo una edad de longevidad, rasgo que apenas tiene protagonismo en la relación hesiódica, cf. West, East Face, 313 s. En el Mahabarata, por ejemplo, la secuencia de edades se corresponde con un acortamiento de la vida humana, que llega a ser dieciséis años en la edad última. Josefo, Ant.Iud. I 108, de quien lo toma Eusebio, PE IX 13 (= fr. dub. 356 M.W.), afirma que los autores de genealogías, entre los que cuenta a Hesíodo junto con Hecateo, Helánico, Acusilao, Éforo y Nicolás de Damasco, atribuían a los primeros hombres una edad de mil ańos. En los versos que iniciaban el Catálogo de las mujeres fr. 1 M.-W. se hacía mención de la duración de la vida de los hombres, pero no está claro en qué términos. 
las razas en el medio épico griego. Pero conviene dejar hablar al poema mismo y a los textos que hacen resonar antes de sacar conclusiones el espectro de sentidos plausibles y la tolerancia de las incoherencias. En una obra que fue conocida metonímicamente por este sustantivo, su aparición en el cuadro áureo no debe considerarse sin consecuencias.

Llamamos en primer lugar la atención sobre lo que podemos interpretar como elaboración del poeta en el sentido de forzar la paradoja del trabajo áureo. El sintagma está precedido de dos adjetivos en función predicativa que subrayan el talante benigno de las labores. La posible redundancia fue sentida ya en la Antigüedad, que conoció un texto que circulaba con la variante epi gaia en lugar del más raro ethelemoi ${ }^{25}$. Pero la secuencia de adjetivos que modalizan la acción verbal está, insistimos, lejos de ser superflua. Puede entenderse que el poeta prepara la inesperada mención del trabajo con sus resonancias férreas neutralizandolas con las cualidades que le dan dignidad de áureo. Los trabajos eran emprendidos a voluntad o gusto y se desarrollaban en plena paz, construyendo de este modo un oxymoron respecto del sentido de la obra en su conjunto: los hombres de esta raza bendita laboran contentos y tranquilos (ethelemoi / hesuchoi). Es más, el adjetivo raro ethelemoi revela una correspondencia inusitada con el automaton, de modo que el motivo de la prosperidad espontánea de la tierra tiene responsión en el carácter de los hombres del metal más noble. Los trabajos áureos tienen el distintivo de la misma tierra que habitan gracias a unos hombres que se aplican a ellos con la disposición optimista de la tierra que trabajan. Los hombres de oro secundan la espontaneidad de la tierra con una espontaneidad propia que hace surgir algo extraordinario, un trabajo sin ponos y sin la degradación servil que el trabajo comporta. Es este un punto de importancia para un poeta que celebra algo que, como ha mostraba elocuentemente Bradford Welles, tenía para los griegos poco que celebrar. Los "trabajos áureos" pueden leerse como la primera piedra en un edificio argumental que asume un plan que, por hablar en términos de la retórica posterior, representa un caso paradójico: el de incitar a los hombres, por mediación de Perses, al trabajo que ha de hacerlos justos y prósperos. Apuntan pues al auténtico centro de la utopía hesiódica, a la ciudad justa. Leemos, en efecto, la misma fórmula en el pasaje que describe el quehacer de los hombres en ella (231), una época y raza en la que este trabajo gozoso y voluntario parece más a propósito. Así pues, en el trabajo que corresponde a su arte, Hesíodo ha enriquecido la vida en tiempos de Crono con un elemento propio de otra edad en introduce en el comienzo mismo de la correlación una suerte de prolepsis que hace sonar ya en los primeros compases un motivo central de la composición.

Y más allá abre una cuestión que definitivamente nos interpela en estos tiempos de oscuridad ilustrada: cómo entender el trabajo de la sociedad feliz que se dará el hombre a sí mismo. La respuesta sigue siendo hesiódica: el acento cae sin excepción en las condiciones que hoy llamamos psico-sociales del trabajo. En un tiempo se llamó alienación a la condición de un trabajador separado de sus medios de trabajo y del

25 West, ad. loc. refiere la entrada de la Suda donde el adjetivo se glosa por medio del anterior, pero señala, a su vez, que es difícil sacar consecuencias. Merece la pena recordar aquí las observaciones de I. Sellschopp, Stilistische Untersuchungen zu Hesiod, (Hamburgo 1934) 39-40 y 71, referentes al estilo de Hesíodo. Según este autor ningún adjetivo en Hesíodo tiene una función decorativa, sobre todo en los términos que describen las relaciones humanas y los valores de la justicia. 
producto del mismo por medio de su salario; la labor revolucionaria debería pasar por una toma de conciencia de esta condición e introducir en el hombre explotado un desasosiego preńado de rebeliones. En el futuro transformado habríamos de esperar que este trabajador reconciliado con sus medios marcharía con gusto al trabajo que dignamente le mantiene. ¡Y es un sucedáneo de ese ánimo voluntarioso para la labor común el que se ha exigido a tanta gente en las "utopías reales" del siglo pasado! 


\section{Série}

\section{Documentos}

Imprensa da Universidade de Coimbra

Coimbra University Press

2009

- $\mathrm{U}$

C • 